\title{
Karakteristik dan Faktor Risiko Obstetrical Brachial Plexus Palsy pada Bayi Baru Lahir
}

\author{
Andreas Vincent Handoyo, Yoyos Dias Ismiarto \\ Bagian Orthopaedi dan Traumatologi \\ Fakultas Kedokteran Universitas Padjadjaran \\ Rumah Sakit Hasan Sadikin, Bandung
}

\begin{abstract}
Abstrak
Obstetrical brachial plexus palsy (OBPP) merupakan cedera sebagian/seluruh plexus brachialis akibat proses kelahiran. Insidensi di negara berkembang berkisar 0,15\%. Faktor risiko meliputi intrapartum dan intrauterin. Dibedakan tiga jenis OBPP yaitu Duchenne Erb, Klumpke, dan whole arm palsy. Penelitian bersifat retrospektif, melihat karakteristik dan faktor risiko terjadinya OBPP di RS. Hasan Sadikin, Bandung, periode Januari 2002-April 2007. Data diperoleh dari catatan medik bagian perinatologi, kemudian dilakukan analisis binary logistic regression. Hasil penelitian menunjukkan insidensi OBPP 0,141\%, seluruhnya Erb palsy dan kehamilan tunggal. Sebanyak $68,75 \%$ presentasi belakang kepala, $50 \%$ lahir spontan, $18,75 \%$ disertai meconeal staining, $62,5 \%$ berat lahir $\geq 3.500$ g, 56,25\% laki-laki, 68,75\% asfiksia, 12,5\% distosia bahu, dan 6,25\% fraktur klavikula. Faktor risiko yang bermakna adalah presentasi kaki (OR 9,357; 95\%CI), letak lintang (OR 5,136; 95\%CI), ekstraksi vakum (OR 5,240;95\%CI), ekstraksi forseps (OR 4,320; 95\%CI), ekstraksi bokong/kaki (OR 14,411; 95\%CI), berat lahir 3.500$3.999 \mathrm{~g}(\mathrm{OR} 4,571 ; 95 \% \mathrm{CI})$, berat lahir $\geq 4.500 \mathrm{~g}(\mathrm{OR} 57,759 ; 95 \% \mathrm{CI})$, asfiksia (OR 5,992; 95\%CI) dan asfiksia berat (OR 6,094; 95\%CI). Sectio Cesarea cenderung protektif $\{$ OR 0,244; 95\%CI; $=0,062(>0,05)\}$. Pada penelitian ini dapat disimpulkan bahwa faktor risiko yang terutama berperan adalah presentasi kaki, ekstraksi bokong, dan berat lahir >4.500 g. [MKB. 2010;42(2):45-51].
\end{abstract}

Kata kunci: Obstetrical brachial plexus palsy, Duchenne Erb palsy, Klumpke palsy

\section{Characteristics and Risk Factors of Obstetrical Brachial Plexus Palsy in Newborn Baby}

\begin{abstract}
Obstetrical brachial plexus palsy (OBPP) is an injury of entire or part of brachial plexus correlated with delivery process. Incidence in developing countries is around $0.15 \%$. Risk factors include intrapartum and intrauterine. Three types of OBPP are Duchenne Erb, Klumpke, and whole arm palsy. This was a retrospective study of characteristic and risk factors of OBPP in Hasan Sadikin Hospital, Bandung, period January 2002-April 2007. Data were collected from perinatology ward medical records, and analyzed using binary logistic regression. OBPP incidence was $0.141 \%$. All were Erb palsy and single pregnancy, $68.75 \%$ were head-occiput posterior presentation, $50 \%$ were spontaneous birth, $18.75 \%$ had meconeal staining, $62.5 \%$ had birth weight $\geq 3,500 \mathrm{~g}, 56.25 \%$ were male, $68.75 \%$ asphyxia, $12.5 \%$ shoulder dystocia, and $6.25 \%$ clavicle fracture. Risk factors significantly correlated were foot presentation (OR 9.357; 95\%CI), transverse fetal position (OR 5.136; 95\%CI), vacuum, forceps, breech/foot extraction (OR 5.240;95\%CI, 4.320; 95\% CI, 14.411; 95\%CI, respectively), birth weight 3,500-3,999 g (OR 4.571; 95\%CI), birth weight $\geq 4,500 \mathrm{~g}(\mathrm{OR} 57.759 ; 95 \% \mathrm{CI})$, asphyxia (ORs 5.992; 95\%CI), and severe asphyxia (OR
\end{abstract}

Korespondensi: dr. Andreas Vincent Handoyo, Bagian Orthopaedi \& Traumatologi, Fakultas Kedokteran Universitas Padjadjaran, Rumah Sakit Hasan Sadikin, Jln. Pasteur no. 38 Bandung, Telp/Fax (022) 2035477,

Email: andreasvincent1@gmail.com 
$6.094 ; 95 \% \mathrm{CI})$. Sectio cesarea tend to have protective effect $\{\mathrm{OR} 0.244 ; 95 \% \mathrm{CI} ; \mathrm{p}=0.062(>0.05)\}$. The important risk factors of OBPP are foot presentation, breech/foot extraction, and birth weight $>4,500 \mathrm{~g}$.

Key words: Obstetrical brachial plexus palsy, brachial plexus, Duchenne Erb palsy, Klumpke palsy, whole arm type palsy

\section{Pendahuluan}

Brachial plexus palsy merupakan suatu paralisis yang diakibatkan oleh cedera pada sebagian atau seluruh pleksus brakialis. Brachial plexus palsy pada bayi baru lahir disebabkan oleh cedera akibat proses kelahiran bayi dan sering disebut sebagai obstetrical brachial plexus palsy (OBPP). ${ }^{1}$ Kasus pertama cedera plexus brachialis pada saat lahir dilaporkan oleh William Smellie tahun 1768 dan William Erb tahun 1877. ${ }^{2}$ Obstetrical brachial plexus injuries umumnya tampak pada saat atau segera setelah lahir. ${ }^{3}$

Penelitian pada insidensi OBPP berbeda di beberapa negara, 0,4 sampai 2,5 setiap 1.000 kelahiran bayi hidup. ${ }^{4}$ Insidensi di Swedia 48 dari 25.736 kelahiran hidup. ${ }^{5}$ Insidensi di Polandia bervariasi antara 0,35 sampai 0,5 tiap 1.000 kelahiran hidup. ${ }^{6-7}$ Insidensi di California berkisar $0,15 \% .{ }^{8}$ Insidensi di Amerika Serikat 0,5 sampai 4,4 kasus setiap 1.000 kelahiran hidup, sedangkan di Prancis dan Saudi Arabia insidensi 1,09 sampai 1,19 tiap 1.000 kelahiran hidup. ${ }^{8}$ Insidensi selama periode 23 tahun (1980 sampai 2002) pada suatu pusat kesehatan tersier di Spartanburg, Amerika Serikat didapatkan sebanyak 85 kasus dalam 89.978 kelahiran hidup per vaginam $(1 / 1.000$ kelahiran hidup). ${ }^{9}$ Insidensi di negara berkembang berkisar $0,15 \%{ }^{10}$ Insidensi di RS Maternity, Kuala Lumpur Malaysia selama periode 12 bulan sebanyak 42 bayi dari 26.176 kelahiran bayi hidup $(1,6 \text { tiap } 1.000 \text { kelahiran hidup })^{8-10}$

Obstetrical brachial plexus palsy dapat terjadi akibat teregangnya satu atau lebih komponen plexus brachialis oleh karena proses penarikan (traksi) pada saat lahir. ${ }^{4}$ Seringkali diakibatkan oleh adanya distosia bahu. Cedera dapat berupa neurapraxia, axonotmesis, maupun neurotmesis. ${ }^{1}$ Beberapa faktor risiko terjadinya OBPP antara lain distosia bahu (45 sampai 53,4\%) dan berat badan lahir (BBL) yang tinggi. ${ }^{1,11-15}$ BBL yang tinggi pada presentasi dahi adalah 3,8 sampai 5,0 kg. Berat lahir 4.001 sampai $4.500 \mathrm{~g}$ memiliki risiko 2,5 kali dibandingkan BBL normal (2.501 sampai $4.000 \mathrm{~g}$ ), sedangkan bayi dengan BBL
$>4.500 \mathrm{~g}$ adalah 21 kali dibandingkan dengan BBL normal. ${ }^{1,7,12}$

Pada presentasi bokong, risiko meningkat 175 kali. Faktor risiko lain antara lain janin dengan pertumbuhan lebih besar dari usia gestasional, diabetes maternal, obesitas dan penambahan berat badan ibu yang berlebihan selama kehamilan, ${ }^{12,16}$ multi paritas, kehamilan multipel, persalinan kala II yang lama (>60 menit), ${ }^{1,16}$ partus presipitatus $(31,8 \%)$, partus lama, partus dibantu/assisted delivery (forsep, vakum), anak sebelumnya lahir dengan OBPP, fraktur klavikula atau distosia bahu, dan fetal distress (7,5\% disertai dengan asfiksia berbagai derajat). Sebanyak $48,8 \%$ bayi baru lahir dengan OBPP memiliki skor APGAR $\leq 7$ pada menit pertama setelah dilahirkan yang menunjukkan adanya gawat janin intrapartum dan merupakan suatu indikasi adanya trauma pada saat lahir. Sectio cesarea mengurangi terjadinya OBPP $\left(\right.$ OR 0,5). ${ }^{7,17}$

Brachial plexus injury sebanyak 94-97\% yang terjadi pada presentasi normal, $1-2 \%$ presentasi bokong, dan $1 \%$ sectio cesarea. Ibu dengan usia lebih dari 35 tahun lebih sering melahirkan bayi dengan brachial plexus palsy dibandingkan yang berusia $\leq 35$ tahun. Bayi laki-laki dan perempuan memiliki frekuensi yang hampir sama. Hampir semua bayi lahir $(97,7 \%)$ diawali spontan tanpa induksi. Sumber lain melaporkan beberapa faktor risiko: berat bayi $>4.000 \mathrm{~g}$, partus presipitatus persalinan kala II ( $<15$ menit), dan ekstraksi vakum. ${ }^{17}$ Insidensi terjadinya brachial plexus injury pada sectio cesarea prelabor 4,1 setiap 10.000 kelahiran, intrapartum 3,0 setiap 10.000 kelahiran, dan persalinan spontan pervaginam 7,7 setiap 10.000 kelahiran.

Terdapat hubungan yang kuat antara BBL dan tinggi badan ibu rendah dengan kecenderungan cedera pada kelahiran bayi pervaginam. Insidensi meningkat dengan semakin rendahnya tinggi badan ibu tetapi kemudian kembali menurun akibat dilakukannya sectio cesarea elektif pada ibu dengan tinggi badan sangat rendah. ${ }^{18}$

Terjadinya brachial plexus injury pada sectio cesarea dapat diakibatkan oleh faktor-faktor in 
utero, misalnya: intrauterine cerebrovascular accidents (strokes), peregangan berlebihan plexus brachialis akibat gerakan fetus, maldevelopment plexus brachialis, tekanan abnormal intrauterin dalam jangka waktu lama akibat uterus bikornu, fibroid uterus, serta infeksi seperti toxoplasmosis, coxsackievirus, mumps, dan pertussis/mycoplasma pneumonie. $^{19}$

Brachial plexus injury berdasarkan segmen saraf yang terkena cedera dibedakan menjadi beberapa tipe: ${ }^{20}$ Erb's palsy/paralysis (Duchene Erb paralysis $(\mathrm{C} 5, \mathrm{C} 6)$, Klumpke's paralysis $(\mathrm{C} 8$, $\mathrm{T} 1)$, whole arm type (C5-T1)). Cedera ringan OBPP biasanya mengalami perbaikan spontan (66 sampai 92\%). Obstetrical brachial plexus palsy dapat disertai (bukan menyebabkan) fraktur klavikula (2 sampai 17\%) dan fraktur humerus $(0,1 \text { tiap } 1.000 \text { kelahiran hidup pervaginam })^{20}$

\section{Metode}

Penelitian ini bersifat retrospektif untuk melihat karakteristik dan faktor-faktor risiko terjadinya OBPP di RS. Hasan Sadikin Bandung. Data bayi baru lahir diperoleh dari catatan medik bangsal perinatologi dari Januari 2002 sampai April 2007 (64 bulan). Dari data tersebut diperoleh informasi mengenai usia ibu, status kehamilan ibu (gravida, para, serta abortus), kenaikan berat badan ibu selama masa kehamilan, tinggi badan ibu, lingkar lengan atas ibu, letak dan presentasi anak, jenis persalinan, jumlah kehamilan (tunggal/ kembar), komplikasi persalinan, lama persalinan kala I dan kala II, kondisi air ketuban (jernih/meconeal staining), berat bayi lahir, panjang bayi lahir, jenis kelamin bayi, lingkar kepala bayi, lingkar dada bayi, ada/tidaknya kelainan kongenital bayi (mikropenis, hipospadia, hidrosefalus, polidaktili, mikrosefal, dan anensefal), kondisi APGAR bayi menit ke-1, kondisi APGAR bayi menit ke-5, kondisi bayi saat segera setelah lahir (asfiksia, sepsis, hiperbilirubinemia), dan kondisi bayi saat 1 minggu setelah lahir (hiperbilirubinemia, sesak napas, sepsis) yang kemudian menjadi variabel dalam pengolahan data. Dari data selama 64 bulan tersebut diperoleh jumlah kelahiran bayi hidup sebanyak 11.324 bayi, baik pervaginam maupun perabdominam (sectio cesarea) yang kemudian dilakukan pengelompokan data dan pembuatan grafik untuk deskripsi karakteristik kejadian OBPP serta analisis binary logistic regression dengan confidence interval (CI) 95\% untuk mencari faktor risiko yang berpengaruh pada insidensi OBPP. Analisis binary logistic regression kedua dilakukan untuk mengetahui odd ratios terhadap masing-masing komponen dari faktor-faktor yang berpengaruh tersebut dengan confidence interval $95 \%$. Analisis statistik dilakukan dengan menggunakan program SPSS $v$ 15.0 for Windows.

\section{Hasil}

Dari data kelahiran bayi hidup selama 64 bulan tersebut didapatkan 16 bayi yang mengalami OBPP. Insidensi OBPP sebanyak 16 dalam 11.324 kelahiran bayi hidup $(0,141 \%)$.

Lima dari 16 bayi $(31,25 \%)$ dilahirkan oleh ibu berusia lebih dari 35 tahun, tiga (18,75\%) bayi dilahirkan oleh ibu primigravida, empat $(25 \%)$ bayi dilahirkan oleh ibu nulipara, dua $(12,5 \%)$ bayi dilahirkan oleh ibu dengan riwayat abortus, dan empat (25\%) bayi dilahirkan pada saat usia kehamilan lebih dari 40 minggu.

Insidensi OBPP tertinggi pada tahun 2003 mencapai 7 kasus dan terendah pada tahun 2002, saat tidak didapatkan kasus OBPP. Seluruhnya (100\%) merupakan Duchenne Erb palsy dan tidak didapatkan kasus Klumpke paralysis maupun whole arm type.

Kenaikan berat badan ibu sebesar 10 sampai $15 \mathrm{~kg}$ selama masa kehamilan didapatkan pada $81,25 \%$ kasus dan tidak didapatkan kenaikan berat badan ibu lebih dari $15 \mathrm{~kg}$.

Bayi dengan OBPP terbanyak pada kelompok tinggi badan 155 sampai $159 \mathrm{~cm}$, hanya 18,75\% bayi dengan tinggi badan kurang dari $155 \mathrm{~cm}$, menunjukkan bahwa sebagian besar tinggi badan ibu cenderung tidak memiliki tinggi badan $<155$ $\mathrm{cm}$ yang merupakan predisposisi cephalopelvic disproportion.

Hanya satu dari enam belas bayi $(6,25 \%)$ dengan lingkar lengan atas ibu lebih dari $30 \mathrm{~cm}$ menunjukkan sebagian besar bayi dilahirkan oleh ibu tanpa obesitas (LLA $\geq 33 \mathrm{~cm}$ pada obesitas). Sebagian besar melahirkan bayi dengan OBPP melakukan pemeriksaan kehamilan dengan baik ( $>4$ kali selama masa kehamilan ke petugas kesehatan (dokter/bidan). Menurut komplikasi ibu, bayi dengan OBP lahir dari ibu hamil dengan anemia $(50 \%)$, preeklampsia $(12,5 \%)$, dan eklampsia (12,5\%). Semua bayi (100\%) lahir dari 


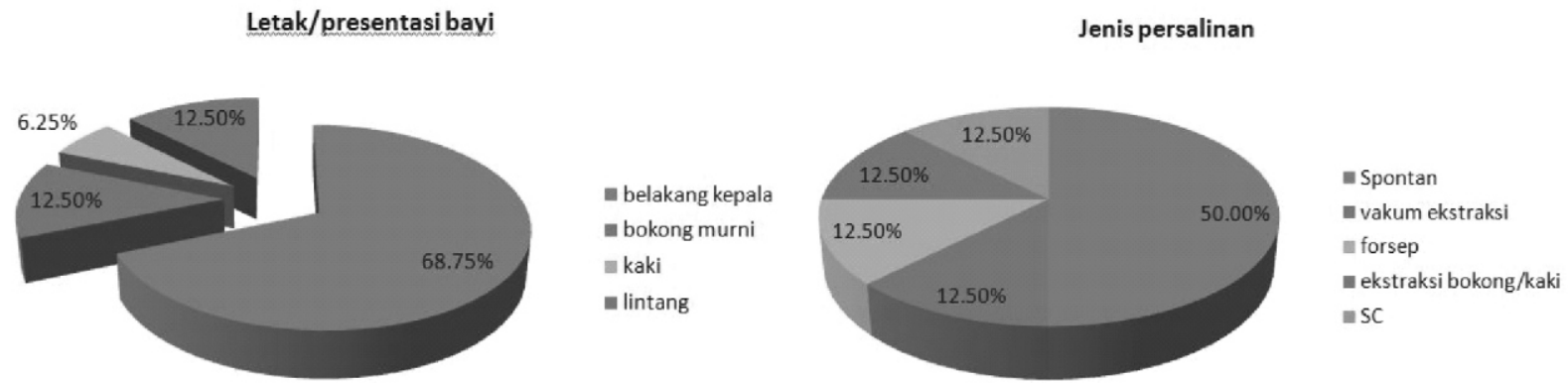

Gambar 1 Persentase Letak/Presentasi Bayi (Kiri) dan Jenis Persalinan pada Kasus OBPP(Kanan)

Gambar 2 Berat Badan Lahir Bayi dengan OBPP

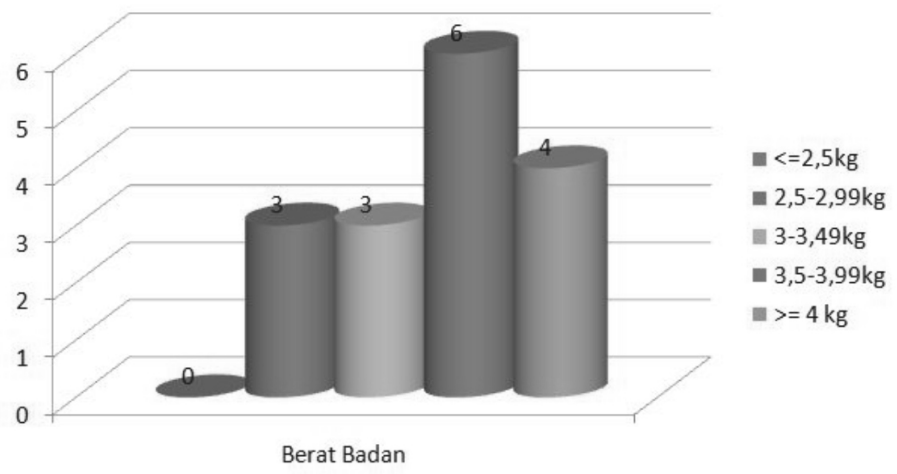

ibu dengan kehamilan tunggal.

Sebesar $57,14 \%$ bayi lahir pervaginam dengan lama persalinan kala I kurang dari 6 jam dan $42,86 \%$ lahir dengan lama persalinan kala I lebih dari 6 jam. Sebanyak 42,86\% lahir dengan lama persalinan kala II antara 10 sampai 30 menit dan 57,14\% lahir dengan lama persalinan kala 2 antara 30 sampai 60 menit. Tidak didapatkan bayi dengan OBPP yang lahir pervaginam dengan kala II kurang dari 10 menit maupun lebih dari 60 menit. Hanya 18,75\% lahir dengan air ketuban meconeal staining, menunjukkan hanya sebagian kecil bayi yang mengalami fetal distress ketika berada dalam kandungan.

Berat badan bayi lahir dengan OBPP (Gambar 2) menunjukkan adanya hubungan terjadinya OBPP pada bayi dengan berat badan 3,5 $\mathrm{kg}$ atau lebih.

Dua (12,5\%) bayi lahir dengan panjang badan $55 \mathrm{~cm}$ atau lebih, sembilan $(56,25 \%)$ bayi lahir dengan panjang badan $50-54,9 \mathrm{~cm}$, tiga $(18,75 \%)$ bayi lahir dengan panjang badan 45 sampai 49,9 $\mathrm{cm}$, dan dua $(12,5 \%)$ bayi lahir dengan panjang badan $<45 \mathrm{~cm}$. Sebesar $56,25 \%$ memiliki jenis kelamin laki-laki dan $43,75 \%$ perempuan.

Sembilan $(56,25 \%)$ bayi lahir dengan nilai
APGAR menit pertama 1 sampai 3, dua (12,5\%) dengan nilai APGAR menit pertama 4-6, dan lima $(31,25 \%)$ bayi lahir dengan nilai APGAR menit pertama $\geq 7$. Pada menit ke-5, tujuh (43,75\%) bayi memiliki nilai APGAR 4 sampai 6 dan sembilan $(56,25 \%)$ bayi memiliki nilai APGAR $\geq 7$. Bayi lahir dengan OBPP disertai beberapa komplikasi persalinan. Sebelas dari $16(68,75 \%)$ bayi lahir yang disertai asfiksia, empat dari $16(25 \%)$ bayi yang disertai hiperbilirubinemia, dua dari enam belas $(12,5 \%)$ bayi disertai dengan distosia bahu, satu dari enam belas $(6,25 \%)$ bayi disertai dengan undescensus testis, dan hanya satu dari enam belas $(6,25 \%)$ bayi disertai dengan fraktur klavikula. Tidak ditemukan komplikasi fraktur humerus.

Tidak didapatkan data lengkap kondisi bayi pada saat 1 minggu setelah persalinan, hanya didapatkan data dari tujuh orang bayi dan ketujuh bayi tersebut dipulangkan tanpa diagnosis OBPP, diperkirakan kondisi ekstremitas bayi dengan OBPP sudah pulih atau membaik.

Analisis yang dilakukan terhadap 25 variabel yang diperkirakan berperan sebagai faktor risiko terjadinya OBPP menggunakan binary logistic regression dengan program SPSS $\mathrm{v} 15.0$ for 
windows didapatkan hanya 5 variabel yang secara signifikan berpengaruh untuk terjadinya OBPP yaitu: letak/presentasi anak, jenis persalinan, berat bayi lahir, nilai APGAR pada menit pertama, dan kondisi asfiksia bayi pada saat lahir. Variabel lain tidak secara signifikan berpengaruh terhadap terjadinya OBPP.

Hasil analisis binary logistic regression untuk letak atau presentasi bayi menunjukkan bahwa presentasi kaki dan letak lintang berpengaruh terhadap terjadinya OBPP dengan OR berturutturut 9,357 (95\% CI; 1,221 sampai 71,682) dan 5,136 (95\% CI; 1,162 sampai 22,698), sedangkan presentasi belakang kepala, puncak kepala, dahi, dan muka serta letak sungsang tidak berpengaruh secara bermakna terhadap terjadinya OBPP.

Hasil analisis binary logistic regression untuk jenis persalinan menunjukkan bahwa ekstraksi vakum meningkatkan risiko terjadinya OBPP dengan OR 5,240 (95\% CI; 1,488 sampai 18,450), ekstraksi forseps meningkatkan risiko terjadinya OBPP dengan OR 4,320 (95\%CI; 0,978 sampai 19,077), dan ekstraksi bokong/kaki meningkatkan risiko terjadinya OBPP dengan OR 14,411 (95\% CI; 3,237 sampai 64,155). Persalinan spontan atau sectio cesarea bukan faktor yang berpengaruh secara signifikan $(p>0,05)$. Meskipun demikian, bayi yang dilahirkan dengan sectio cesarea juga dapat terjadi OBPP (12,5\%), mungkin disebabkan oleh faktor intrauterin seperti gerakan fetus dalam rahim selama kehamilan atau maldevelopment plexus brachialis dan tidak selalu disertai dengan fetal distress.

Hasil analisis binary logistic regression untuk berat badan lahir bayi memberikan risiko yang bermakna untuk terjadinya OBPP pada kelompok BBL 3.500 sampai $3.999 \mathrm{~g}$ dengan OR 4,571 (95\% CI; 1,659 sampai 12,598), dan kelompok berat bayi lahir $4.500 \mathrm{~g}$ ke atas dengan OR 57,759 (95\% CI; 15,914 sampai 209,630). Kelompok BBL 4.000 sampai $4.499 \mathrm{~g}$ cenderung mengakibatkan OBPP dengan ORs 3,780 95\% CI tetapi tidak bermakna secara statistik. Sedangkan kelompok berat bayi lahir 2.500 sampai $3.499 \mathrm{~g}$ cenderung memberikan efek protektif dengan ORs 0,389 95\% CI tetapi tidak bermakna secara statistik.

Hasil analisis statistik dengan binary logistic regression untuk nilai APGAR menit pertama bayi dan kondisi asfiksia bayi pada saat segera setelah lahir memberikan risiko yang bermakna untuk terjadinya OBPP secara bersamaan dengan terjadinya asfiksia OR 5,992 (95\% CI; 2,080 sampai 17,258$)$ dan terjadinya asfiksia berat OR 6,094 (95\% CI; 2,267 sampai 16,384). Hal ini mungkin diakibatkan kecenderungan dilakukan tarikan lebih kuat untuk melahirkan bayi lebih cepat pada bayi dengan asfiksia dengan/tanpa bantuan alat (vakum, forseps) yang cenderung mengakibatkan cedera pada pleksus brakialis.

\section{Pembahasan}

Insidensi OBPP di RS. Hasan Sadikin Bandung, $0,141 \%$ sesuai dengan insidensi yang terjadi di negara berkembang. Karakteristik insidensi OBPP tersebut memiliki kecenderungan tidak dipengaruhi umur dan status gravida-para-abortus ibu, serta jarang terjadi pada bayi yang dilahirkan dengan umur kehamilan kurang dari 37 minggu. OBPP mengalami penurunan insidensi dari tahun 2003 sampai 2007. Seluruh insidensi berupa Duchenne Erb palsy dengan mayoritas terjadi pada kenaikan berat badan ibu 10 sampai $15 \mathrm{~kg}$ dan ibu dengan tinggi badan 155 sampai $159 \mathrm{~cm}$. OBPP jarang terjadi pada bayi dengan ibu yang memiliki lingkar lengan atas kurang dari $20 \mathrm{~cm}$ dan mayoritas dilahirkan oleh ibu dengan riwayat pemeriksaan kehamilan yang baik. Sebanyak $50 \%$ bayi dengan OBPP lahir dari ibu dengan anemia, seluruhnya dilahirkan oleh ibu dengan kehamilan tunggal, mayoritas memiliki presentasi belakang kepala dan lahir dengan lama persalinan kala I dan kala II yang normal, 50\% lahir secara spontan, serta hanya sebagian kecil disertai fetal distress. Mayoritas terjadi pada bayi dengan berat badan lahir $3,5 \mathrm{~kg}$ atau lebih, mayoritas memiliki panjang badan lahir 50-54,9 cm, insidensi antara laki-laki dan perempuan relatif sama, cenderung terjadi pada bayi dengan lingkar kepala dan lingkar dada normal, mayoritas disertai dengan kondisi asfiksia, dan hanya sebagian kecil disertai distosia bahu $(12,5 \%)$ atau fraktur klavikula $(6,25 \%)$.

Faktor risiko yang signifikan berpengaruh terhadap terjadinya OBPP di RS. Hasan Sadikin Bandung adalah presentasi kaki (OR 9,357; 95\% CI), letak lintang (OR 5,136; 95\% CI), ekstraksi vakum (OR 5,240;95\% CI), ekstraksi forseps (OR 4,320; 95\% CI), ekstraksi bokong/ kaki (OR $14,411 ; 95 \% \mathrm{CI})$, berat bayi 3.500 sampai $3.999 \mathrm{~g}$ (OR 4,571; 95\% CI), berat bayi $4.500 \mathrm{~g}$ ke atas (OR 57,759; 95\%CI), kondisi asfiksia (OR 5,992; 95\% CI) dan asfiksia berat (OR 6,094; 95\%CI). 
Sectio cesarea cenderung memberikan efek protektif tetapi tidak bermakna secara statisik $\{$ OR 0,244; $95 \%$ CI; $\mathrm{p}=0,062(>0,05)\}$. Berat bayi lahir 4.000-4.499 g cenderung menyebabkan OBPP tetapi tidak bermakna secara statistik $\{\mathrm{OR}$ $3,780 ; 95 \% \mathrm{CI} ; \mathrm{p}=0,199(>0,05)\}$.

Hasil penelitian dapat disimpulkan bahwa secara umum karakteristik OBPP di RS. Hasan Sadikin Bandung sesuai dengan literatur yang ada. Faktor risiko yang terutama berperan adalah presentasi khaki, ekstraksi bokong, dan berat bayi lebih dari $4.500 \mathrm{~g}$.

Saran-saran yang harus dilakukan yaitu perlu dilakukannya sosialisasi kepada masyarakat luas mengenai OBPP dan faktor-faktor risiko untuk mengurangi insidensinya, dan perlu dilakukan penelitian yang lebih lanjut mengenai penanganan konservatif dan operatif kasus OBPP.

\section{Daftar Pustaka}

1. Concepcion JS, Nasr H, Conway A, Concepcion C. Neonatal brachial plexus palsies (diunduh 20 September 2007). Tersedia dari: http:// www. emedicine.com/pmr/plexopathy.htm.

2. St. Louis Children's Hospital-Washington University School of Medicine. Brachial plexus palsy (diunduh 18 September 2007). Tersedia dari: http://www.brachialplexus.wustl.edu. mht.

3. Benjamin K. Part 2. Distinguishing physical characteristics and management of brachial plexus injuries. J Adv Neonatal Care. 2005;5(5):24051.

4. Tachdjian MO. Clinical pediatric orthopedics: the art of diagnosis and principles of management. Stamford: Appleton \& Lange; 1997.

5. Becker MHJ, Lassner F, Bahm J, Ingianni G, Palua N. The cervical rib: a predisposing factor for obstetric brachial plexus lesions. JBJS. 2002 Juli;5 (8):740.

6. Gosk J, Rutowski R. The influence of the risk factors on the localisation and degree of severity in perinatal brachial plexus lesions. Adv Clin Exp Med. 2006;2(15):303-8.

7. Gilbert WM, Nesbitt TS, Danielsen B. Associated factors in 1611 cases of brachial plexus injury. J Obstet Gynecol. 1999April;93(4):74-9.
8. Boo NY, Lye MS, Kanchanamala M, Ching CL. Brachial plexus injuries in malaysian neonates: incidence and associated risk factors. J Tropical Pediatr. 1991;37(6):327-30.

9. Chauhan SP, Rose CH, Gherman RB, Magann EF, Holland MW, Morrison JC. Brachial plexus injury: a 23-years experience from a tertiary center. Am J Obstetri Gynecol. 2005 Juni;6 (192): 1795-800.

10. Heise CO, Gherpelli JRD. Prognostic relevance of risk factors for obstetrical brachial plexopathy. J Arq Neuropsiqulatr. 2006;64(1):30-4.

11. Waters PM. The upper limb. Dalam: Morrissy RT, Weinstein SL, penyunting. Lovell and Winter's pediatric orthopaedics. Edisi ke-5. Philadelphia: Lippincott Williams \& Wilkins, 2001. hlm.102-6.

12. Sutcliffe TL. Brachial plexus injury in the newborn. NeoReviews. 2007 Juni;6(8):1-8.

13. Mehta SH, Blackwell SC, Bujold E, Sokol RJ. What factors are associated with neonatal injury following shoulder dystocia?. J Perinatol. 2006; 26:85-8.

14. Adegbehingbe OO, Owa JA, Kuti O, Oginni LW. Orthopaedic birth trauma: a reflection of current perinatal care. Int J Gynecol Obstetr 2007; 2(6): 15-8.

15. Blickstein I, Ben-Arie A, Hagay ZJ. Antepartum risk of shoulder dystocia and brachial plexus injury for infants weighing $4.200 \mathrm{~g}$ or more. J Gynecol Obstetr Investigation. 1998;45:77-80.

16. Bryant DR, Leonardi MR, Landwehr JB, Bottoms SF. Limited usefulness of fetal weight in predicting neonatal brachial plexus injury. Am J Obstetri Gynecol 1998 Sept;179(3):686-9.

17. Hudic I, Fatuzic Z, Sinanovic O, Skokic F. Etiological risk factors for brachial plexus palsy. J Maternal-Fetal Neonatal Med. 2006 Oct;19(10): 655-62.

18. Gudmundsson S, Henningsson AC, Lindqvist P. Correlation of birth injuries with maternal height and birthweight. BJOG. 2005 Juni; 112(6):7647.

19. Gherman RB, Goodwin TM, Ouzounian JG, Miller DA, Paul RH. Brachial plexus palsy associated with caesarean section: an in utero injury? Am J Obstetri Gynecol. 1997 Nov; 5(177):1162-4.

20. Salter RB. Textbook of disorders and injuries of the musculoskeletal system. Edisi ke-3. Philadelphia: Lippincott William \& Wilkins; 